\title{
Chemical structure and antioxidant activity of cephalopod skin ommochrome pigment extracts
}

\author{
Dania Marisol ESPARZA-ESPINOZA, Hisila del Carmén SANTACRUZ-ORTEGA², \\ Jesús Enrique CHAN-HIGUERA ${ }^{1}$, José Luis CÁRDENAS-LÓPEZ ${ }^{1}$, Armando BURGOS-HERNÁNDEZ , \\ Ángel A. CARBONELL-BARRACHINA³ , Josafat Marina EZQUERRA-BRAUER ${ }^{1 *}$
}

\begin{abstract}
Significant opportunities exist in the use of seafood by-products to create new beneficial products. Moreover, cephalopod skin is a good source of bioactive compounds. The present study compares the chemical structure properties and antioxidant activity of pigments extracted from the skin of Octopus vulgaris (OVS) and Dosidicus gigas (DGS) with methanol-HCl (T1) and ethanol- $\mathrm{HCl}$ (T2). The solubility and spectroscopic analysis (UV-Vis and ${ }^{1} \mathrm{H} N M R$ ) indicated that extracted pigments belonged to the ommochrome family. Xanthommatin, dihydroxanthommatin, and kynurenine compounds were identified in the extracts using correlated homonuclear spectroscopy (COSY). The results showed that OVS yielded a higher recovery rate of pigments with antioxidant activity (DPPH, ABTS, and FRAP) than DGS in both solvents. T1 extracted the highest level of antioxidant pigments. The kynurenine proportion and proton peaks observed at 3.0-5.0 ppm (amino-aromatics) in the ${ }^{1} \mathrm{H}$ NMR spectra may explain the differences in antioxidant activity of OVS and DGS.
\end{abstract}

Keywords: antioxidant; cephalopod skin; chemical structure; ommochrome pigments.

Practical Application: Cephalopod are a source of compounds commonly associated with health benefits. This study provides information about the chemical characteristics of antioxidant ommochromes from the skin of cephalopods. This work also establishes the effect of the nature of solvents by comparing the activities of methanolic and ethanolic extracts. The results suggest a potential for further research in order to select the most effective cephalopod species in terms of its antioxidant activity.

\section{Introduction}

New food products that offer greater nutritional content and possible health benefits to consumers are a global trend (Aryee \& Boye, 2015). In addition, clean label products (that is, virtually free of artificial additives) are demanded and preferred by consumers (Asioli et al., 2017). Hence, food science has focused on research into natural compounds that can be substituted for food additives and have potential against the development of diseases. Antioxidant activity has been widely regarded as a potential factor that helps prevent the development of chronic degenerative illnesses mediated by free-radical production (Vodnar et al., 2017). Moreover, protection from lipid oxidation is a critical factor in the quality of many foods, mainly those rich in unsaturated lipids (Shahidi \& Zhong, 2015). Oxidative reactions lead to a change of colour, odour, and flavour of foods products, causing economic burden (Aziz \& Karboune, 2018). Hence, different preservatives have been used to prevent quality deterioration during processing and storage of foodstuffs. Although synthetic antioxidants are highly effective, there is uncertainty about their negative impact on human health (Kumar et al., 2017). Thus, the search for compounds that can act as antioxidants has led research into the depths of the ocean, due to their potential to be used as preventive molecules against free radicals and oxidative reactions (Shahidi, 2006).
Ommochromes, a group of pigments found on the skin of cephalopods, have been evaluated as a source of useful nutraceuticals in the food industry. Ommochrome compounds can act as electron donors and stabilise free radicals (Romero \& Martínez, 2015). In previous studies, the antioxidant activity of ommochromes has been proven in both food models and against free radicals (Aubourg et al., 2016; Ezquerra-Brauer et al., 2016, 2017; Chan-Higuera et al., 2019a). Recently, the mutagenic activity of ommochromes has been evaluated as a form of toxicity in vitro (Ezquerra-Brauer et al., 2017; Chan-Higuera et al., 2019b).

The extraction efficiency of bioactive compounds depends on, among other factors, the extraction solvent (Ngo et al., 2017). The solubility of an antioxidant compound in a given solvent depends on its chemical characteristics, including polarity. Most solvents used to extract bioactive compounds from cephalopods are aqueous solutions of ethanol, methanol, acetone, and hexane; for example, ethanolic extracts of squid (Loligo duvauceli) ink exhibited higher antioxidant activity than hexane extracts (Fatimah \& Rabeta, 2017). In contrast, antimutagenic activity assessed in octopus (Paraoctopus limaculatus) tentacle extracts was higher in hexane than in methanol and acetone extracts (Cruz-Ramírez et al., 2015). Until now, pigmented extracts 
with antioxidants were obtained from squid skin using acidified ethanol (Aubourg et al., 2016) and acidified methanol (ChanHiguera et al., 2019a, c). Moreover, the main ommochromes identified in squid skin pigmented extracts are xanthommatin and dihydroxhantommatin (Chan-Higuera et al., 2019c).

Little information is available on alternative sources of these compounds. The present research includes the first attempt to determine the potential use of octopus skin as a source of antioxidant compounds by comparing the chemical structure and in vitro antioxidant activity of acidified methanol (T1) and acidified ethanol (T2) pigments extracted from the skin of Octopus vulgaris (OVS) and Dosidicus gigas (DGS).

\section{Materials and methods}

\subsection{Chemical and reagents}

All reagents and solvents used in this research were of good analytical grade and were purchased from J.T. Baker (Mexico, Mexico), Sigma Aldrich (Steinheim, Germany), Merck (Darmstadt, Germany), and ABATEC (Jalisco, Mexico).

\subsection{Sample preparation}

Ten octopuses (O. vulgaris) and ten squid (D. gigas) were purchased from local fishers on the coast of Hermosillo, Sonora, Mexico (28 $\left.49^{\prime} 22^{\prime \prime} \mathrm{N} ; 111^{\circ} 56^{\prime} 27^{\prime \prime} \mathrm{W}\right)$. Specimens were stored in an iced bed system and transported to the Seafood Laboratory. The length and weight of octopus specimens ranged from 45 to $50 \mathrm{~cm}$ and 2.5 to $3.0 \mathrm{~kg}$, respectively, whereas squid ranged from 100 to $150 \mathrm{~cm}$ and 4 to $6 \mathrm{~kg}$, respectively. The skin was collected manually from octopus heads (about $15 \mathrm{~cm}$ ) and squid mantles (about $50 \mathrm{~cm}$ ). The skin was cut into small pieces and freeze dried (LABCONCO Freeze Dry, Kansas City, MO, USA). One hundred milligram portions of freeze-dried skin were placed in polyethene bags and stored at $-20 \pm 2{ }^{\circ} \mathrm{C}$ until use.

\subsection{Pigment extraction}

Acidified methanol (99:1 methanol:HCl, T1) and acidified ethanol (99:1 ethanol:HCl, T2) were used to extract pigment compounds from freeze-dried skin samples. The samples were extracted according to Chan-Higuera et al. (2019a). Briefly, $100 \mathrm{mg}$ of sample was mixed with a solvent in a 1:20 (w:v) ratio, sonicated for $5 \mathrm{~min}$ (IKA-UltraTurrax T-25, Germany), and then centrifuged (Biofuge Stratos, Thermo Scientific, Germany) at $10,000 \times g$ for $15 \mathrm{~min}$. This process was repeated three times. The pigment extracts were concentrated by removing the solvent using a rotary evaporator (R-100, Büchi, Switzerland); subsequently, samples without solvent were incubated at room temperature for 1-3 days under vacuum until dry. The dried samples were stored at $-20{ }^{\circ} \mathrm{C}$ until use. The dried yield was calculated gravimetrically using the weight of the skin sample as a reference. The final treatments were: OVS-T1 (octopus skin pigments extracted with methanol-HCl), OVS-T2 (octopus skin pigments extracted with ethanol-HCl), DGS-T1 (squid skin pigments extracted with methanol-HCl), and DGS-T2 (squid skin pigments extracted with ethanol- $\mathrm{HCl}$ ).

\subsection{Physico-chemical analysis}

The protein content was determined in dried pigment extracts solubilised in methanol and using the Bradford method (Bradford, 1976). A bovine serum solution $(1 \mathrm{mg} / \mathrm{mL})$ was employed as standard.

The nature of the methanolic and ethanolic extracts was determined by a solubility test using different solvents (Kiyomoto et al., 1969), using $5 \mathrm{~mL}$ of the following solvents: acetone, ethyl ether, chloroform, 77\% aqueous sulphuric acid, and methanol-2\% $\mathrm{HCl}$. In each solvent, $5 \mathrm{mg}$ of dried pigment extract was dissolved and stirred for $5 \mathrm{~min}$ at $24^{\circ} \mathrm{C}$ (Van den Branden \& Decleir, 1976).

The UV-Visible spectra of octopus and squid pigment extracts were obtained using a Varian Cary 5 UV-Vis spectrophotometer (Cary 50 UV-VIS, Agilent Technologies, Ciudad de México, Mexico) over the wavelength range from 200 to $600 \mathrm{~nm}$. The blank solution used was methanol (Chan-Higuera et al., 2019a).

Nuclear magnetic resonance of the proton $\left({ }^{1} \mathrm{H}-\mathrm{NMR}\right)$ spectra of the dried pigment extracts was obtained in a Bruker Avance 400 NMR spectrometer (Billerica, MA, USA). Samples $(1 \mathrm{mg})$ were dissolved in a mixture of deuterium chloride (DCl) and deuterium oxide $\left(\mathrm{D}_{2} \mathrm{O}\right)$. Typical parameters for spectrum acquisition were: $2 \mathrm{~s}$ (delay), $4.56 \mathrm{~s}$ (acquisition time), $5 \mathrm{ls}$ (pulse), 30 (flip angle), 64 (number of scans), $3.35 \mathrm{kHz}$ (spectral). The pigments were analysed additionally by two-dimensional (2D) correlated homonuclear spectroscopy (COSY). COSY spectra were acquired with $1.5 \mathrm{~s}$ (delay), 4 (scans/increment), $3.97 \mathrm{kHz}$, and $1024 \times 256$ data points. The data were analysed using the software program MESTREC (MesrReNova v9.0.1-13254, Mestrelab Research S.L., Spain).

\subsection{Antioxidant activity}

The in vitro antioxidant activity of the dried samples was determined by four antioxidant assays, namely, the 2,2-diphenyl1-picrylhydrazyl (DPPH) (Brand-Williams et al., 1995), 2,2'-azino-bis-(3-ethylbenzothiazoline-6-sulfonic acid) (ABTS) (Re et al., 1999), ferric reducing antioxidant power (FRAP) (Benzie \& Strain, 1999), and the oxygen radical absorbance capacity (ORAC) (Prior et al., 2003) assays.

The DPPH assay was carried out by dissolving $20 \mu \mathrm{L}$ samples $(2.5,1.3,0.75,0.38$, and $0.19 \mathrm{mg} / \mathrm{mL})$ in $200 \mu \mathrm{L} \mathrm{DPPH}$ solution $\left(1.25 \mathrm{mg} / 50 \mathrm{~mL}\right.$ methanol). The samples were incubated at $25^{\circ} \mathrm{C}$ for $30 \mathrm{~min}$, and then the absorbance was read at $517 \mathrm{~nm}$ using a UV spectrophotometer (Multiskan GO, Thermo Scientific). The scavenging activity percentage inhibition of the samples was calculated from $\mathrm{Abs}_{517 \mathrm{~nm}}$ (\% inhibition/mg sample).

For the ABTS assay, the stock solution of ABTS radical consisted of $7 \mathrm{mmol}$ of ABTS in $5 \mathrm{~mL}$ water and $0.14 \mathrm{mmol}$ potassium persulfate, kept in the dark at room temperature $(16 \mathrm{~h})$. The working solution was freshly prepared $(1 \mathrm{~mL}$ ABTS stock solution: $80 \mathrm{~mL}$ ethanol) to obtain an Abs734nm value of 0.70 on the day of analysis. An aliquot of $270 \mu \mathrm{L}$ of freshly prepared working solution of ABTS •+ was mixed with $20 \mu \mathrm{L}$ of each sample $(2.4,1.2,0.6,0.3$, and $0.1 \mathrm{mg} / \mathrm{mL})$ and left in the dark at room temperature for $30 \mathrm{~min}$ before its absorbance was 
recorded at $734 \mathrm{~nm}$ using a UV spectrophotometer (Multiskan GO, Thermo Scientific). The percentage inhibition of the samples was calculated from the $\mathrm{Abs}_{734 \mathrm{~nm}}$ (\% inhibition/mg sample).

The results for DPPH and ABTS radicals were expressed as the concentration of the sample required to inhibit $50 \%$ of $\mathrm{DPPH}$ or ABTS radicals $\left(\mathrm{IC}_{50}\right)$. The $\mathrm{IC}_{50}$ was determined using an inhibition curve constructed from percentage inhibition values obtained for different concentrations of pigment extracts.

The FRAP assay was performed using a mixture of $10 \mathrm{mM}$ 2,4,6-tri(2-pyridyl)-s-triazine (TPTZ) in $40 \mathrm{mM} \mathrm{HCl}, 25 \mathrm{~mL}$ acetic acid-sodium acetate buffer (pH 3.4), and $2.5 \mathrm{~mL}$ of $20 \mathrm{mM}$ $\mathrm{FeCl}_{3}: \mathrm{H}_{2} \mathrm{O}$ as the working FRAP solution. An aliquot of $20 \mu \mathrm{L}$ of the samples $(1 \mathrm{mg} / \mathrm{mL})$ was mixed with $280 \mu \mathrm{L}$ FRAP working solution and incubated at $25^{\circ} \mathrm{C}$ in the dark for $30 \mathrm{~min}$ before its absorbance was recorded at $638 \mathrm{~nm}$ using a UV spectrophotometer (Multiskan GO, Thermo Scientific). Trolox was used as the standard and the results were expressed as TE $\mu \mathrm{mol} / \mathrm{g}$ sample.

The ORAC assay was determined by followed the fluorescence fall of fluorescein over $60 \mathrm{~min}$ at $37^{\circ} \mathrm{C}$ in the presence of 2,20-Azobis (2-amidinopropane) dihydrochloride (AAPH) as a precursor for reactive oxygen substances. Briefly $0.1 \mathrm{~mL}$ of each extract $(0.5 \mathrm{mg} / \mathrm{mL})$ were mixed with $1.7 \mathrm{~mL}$ of $75 \mathrm{mM}$ phosphate buffer ( $\mathrm{pH} 7.3$ ), $0.1 \mathrm{~mL}$ of $0.36 \mathrm{M} \mathrm{AAPH}$ and $0.1 \mathrm{~mL}$ of $0.048 \mathrm{mM}$ fluorescein. The loss of fluorescence was recorded at $485 \mathrm{~nm}$ (excitation) and $520 \mathrm{~nm}$ (emission) in a spectrophotometer Cary Eclipse (Agilent Technologies, Ciudad de Mexico, Mexico). Trolox was employed as standard, and the results were expressed as $\mu \mathrm{mol}$ TE per g sample.

\subsection{Statistical analysis}

The statistical design included the employment of replicates to minimise the variation occurring between samples (Fay \& Gerow, 2013). Descriptive statistics were used to analyse spectroscopic data (UV-VIS and ${ }^{1} \mathrm{H}-\mathrm{NMR}$ ). A wholly randomised, two-way analysis of variance (ANOVA) statistical design was carried out for the protein content, solubility test, and antioxidant activity, using the organism (octopus and squid skin) and extraction system (methanol- $\mathrm{HCl}$ and ethanol- $\mathrm{HCl}$ ) as factors. The experimental design and statistical analysis were carried out using JMP software (SAS, Cary, NC, USA). Differences between means were compared using Tukey's test $(p \leq 0.05)$.

\section{Results and discussion}

\subsection{Physico-chemical analysis}

The extraction of octopus and squid pigments was carried out using two different solvents, acidified methanol and acidified ethanol, with the highest yield obtained in both organisms when methanol-HCl was used as the extraction solvent. The order of the yield after drying was OVS-T1 > DGS-T1 > OVS-T2 > DGS-T2. Similarly, Cruz-Ramírez et al. (2015) reported that methanol was one of the most effective organic solvents for the extraction of compounds from an octopus.

The yield values obtained in this study (OVS-T1, 206 mg/100 g; OVS-T2, 104 mg/100 g; DGS-T1, 111 mg/100 g;
DGS-T2, $72 \mathrm{mg} / 100 \mathrm{~g}$ ) were lower than those detected previously in D. gigas skin (Chan-Higuera et al., 2019a). The differences in pigment recovery could be attributed to intrinsic variations within species, stocks, and strains, among others factors, which can account for differences in the chemical compound content in cephalopods (Özyurt et al., 2006; Zumholz et al., 2006). The differences detected among species may be attributed to the specific living conditions and behaviours of each organism. Octopus are highly sedentary, whereas squid are highly active, which may affect the chemical composition of their tissues (Morales et al., 2000).

The protein content, physical characteristics and solubility of the obtained extracts were also analysed. The negligible levels of protein and reddish colour suggests that some types of ommochrome compounds are constituents of the cephalopod skin pigments obtained (Deravi et al., 2014). Moreover, all extracts were insoluble in acetone, ethyl ether, or chloroform, but soluble in $77 \% \mathrm{H}_{2} \mathrm{SO}_{4}$; therefore, the presence of carotenoids and melanins was ruled out. In contrast, the high solubility in $2 \%$ methanol- $2 \% \mathrm{HCl}$ led to the assumption that the main compounds present in the obtained pigmented extracts may pertain to the same ommochrome group (Van den Branden \& Decleir, 1976).

To confirm the presence of ommochromes in extracts of octopus and squid skin, their absorbance spectra were obtained using UV-Visible spectrophotometry (Figure 1). The UV-Visible spectra of OVS and DGS extracts were similar; all showed two peaks, one at $266 \mathrm{~nm}$ (major peak) and another at $518 \mathrm{~nm}$ (wide band $428-630 \mathrm{~nm}$ ). The spectra matched the ommatin group of ommochromes (Sawada et al., 2000). The wide bands (360-650 nm) are attributed to a combination of different ommochrome compounds (Liu et al., 2012; Francikowski et al., 2019). The main absorbance peaks detected in ommochromes can shift; however, the most common shifts reported for xanthommatin and dihydroxanthommatin are observed in the UV, near UV, and 430-520 nm ranges (Riou \& Christidès, 2010; Figon \& Casas,

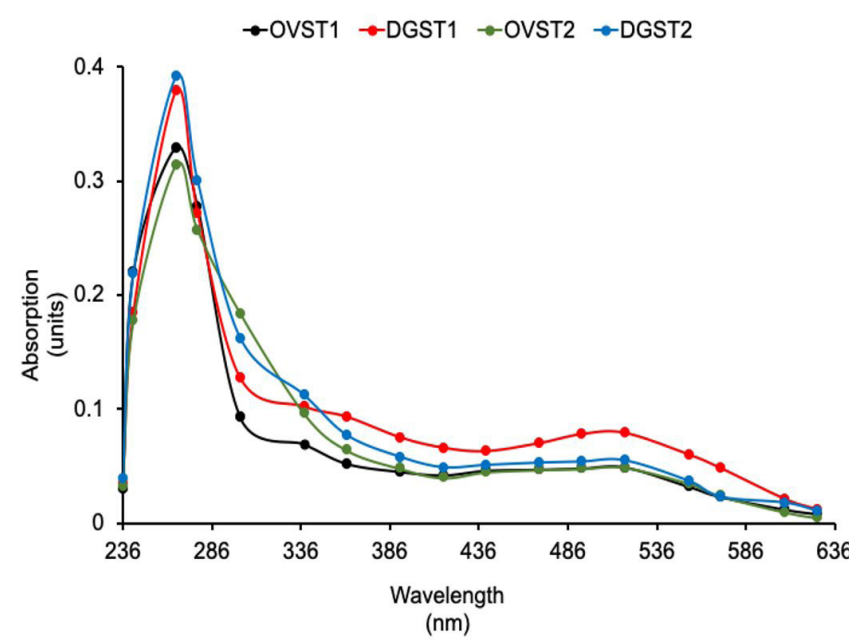

Figure 1. UV-Vis spectra of pigments extract from the skin of cephalopods: OVS-T1, methanolic extracts from octopus; OVS-T2, ethanolic extracts from octopus; DGS-T1, methanolic extracts from squid; DGST-T2, ethanolic extracts from squid. 
2018). The absorbance reported for an ommochrome precursor, kynurenine, is $248-363 \mathrm{~nm}$ (Romero \& Martínez, 2015). Therefore, the spectra obtained suggest the presence of ommochrome compounds, mainly xanthommatin, dihydroxanthommatin, and kynurenine, in the extracted pigments.

${ }^{1} \mathrm{H}-\mathrm{NMR}$ spectroscopy analysis was employed to provide information regarding the chemical composition and conformation of the obtained pigments (Figure 2). In a recent study, using ${ }^{1} \mathrm{H}-\mathrm{NMR}$ spectra Chan-Higuera et al. (2019c) revealed the presence of xanthommatin (11-(3-amino-3-carboxypropanoyl)1-hydroxy-5-oxo-5H-pyrido[3,2 a]phenoxazine-3-carboxylic acid) and its derivatives (hydro- and dihydroxanthommatin) in antioxidant pigments from the squid skin. These pigments are considered to be tryptophan-derived metabolites that come from the kynurenine pathway (Daniels \& Reed, 2012). Although the typical ${ }^{1} \mathrm{H}$-NMR can aid in the elucidation of the structure, the 2D-NMR spectroscopic COSY method can be used to obtain even more detailed structural information of any molecule (Englert et al., 1990).
The ${ }^{1} \mathrm{H}-\mathrm{NMR}$ spectra of the four pigmented extracts (Figure 2) were compared with previous works and spectral databases. The signals corresponding to the functional groups in the phenoxazone core zone (spectra portions between $\delta 9.0$ and $6.5 \mathrm{ppm}$ ) were of interest because these groups are the basic structure of ommochromes. The signals detected for each pigment were similar; however, the intensity of some peaks varied. The portions of spectra between $\delta 9.0$ and $6.5 \mathrm{ppm}$ are associated with aromatic protons and amino group protons. The chemical shifts from $\delta 5.0$ to $3.0 \mathrm{ppm}$ indicate aromatic amine groups. Signals observed at $\delta 3.0-2.0 \mathrm{ppm}$ indicate protons bound to carbonyl and nitrogen compounds. The last section $(\delta 2.0-0.5 \mathrm{ppm})$ indicates aliphatic compounds. Resonances that are significant in identification are shown in Figure 3.

The COSY spectrum (Figure 3) supports the presence of a phenoxazone core in the pigment extracts. Most notably, the spectrum reveals an 11-3(-amino-3-carboxypropanoyl)-1hydroxy -5-oxo-5H-pyrido[3,2-a]phenoxazine-3-carboxylic acid (cross-peaks D, F, G, H, I). The spectrum also reveals the presence of 11-(3-azaniumyl-3-carboxylatopropanoyl)-1,5- (a)

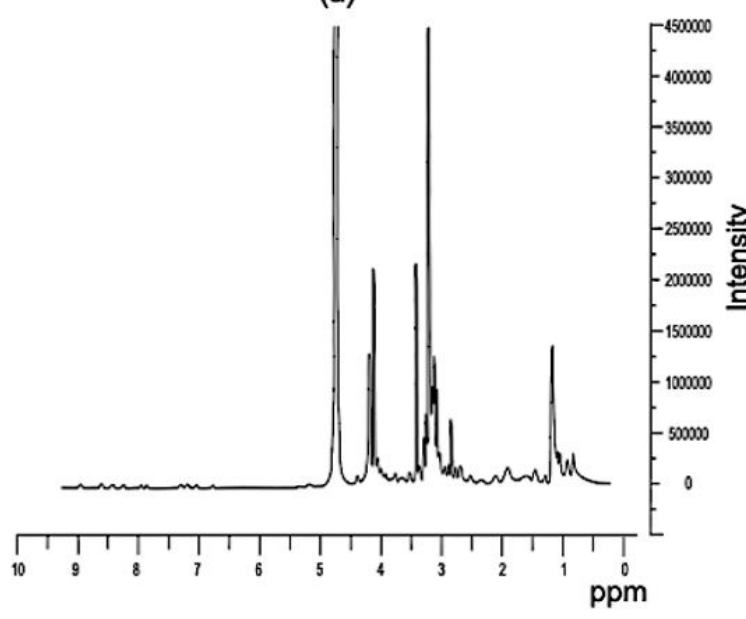

(b)

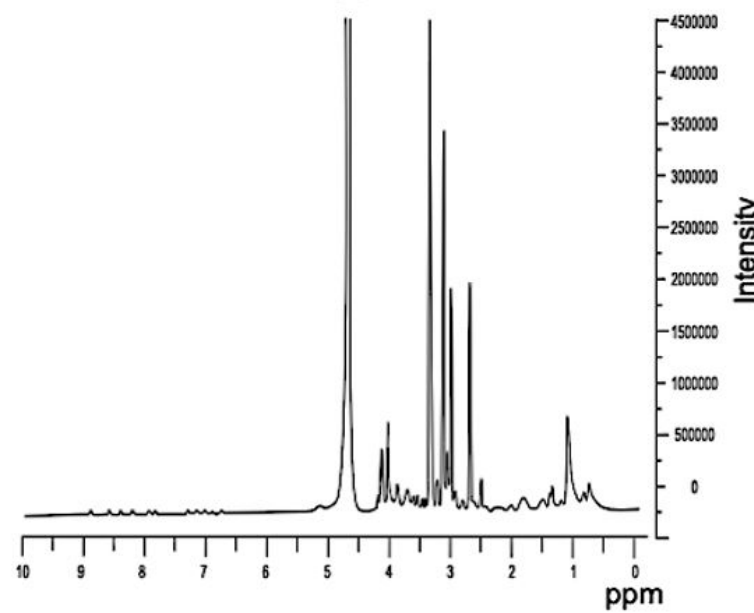

(c)

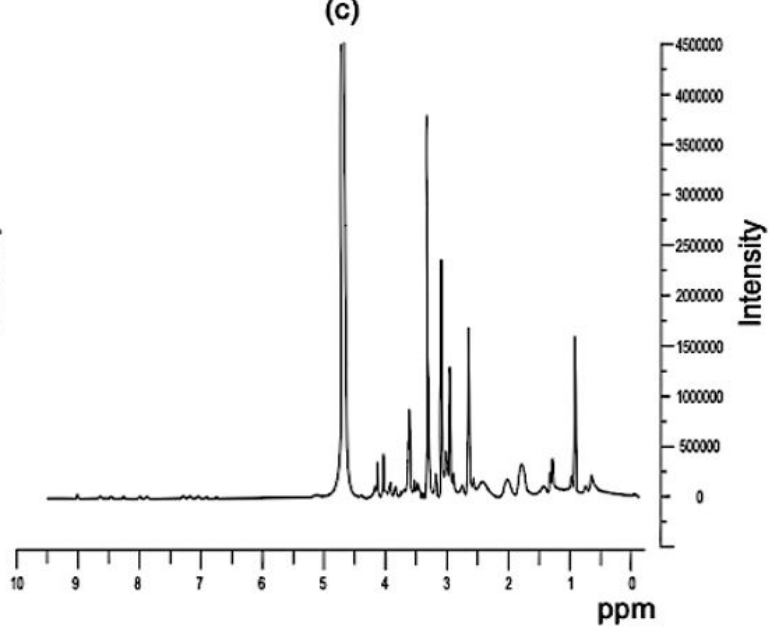

(d)

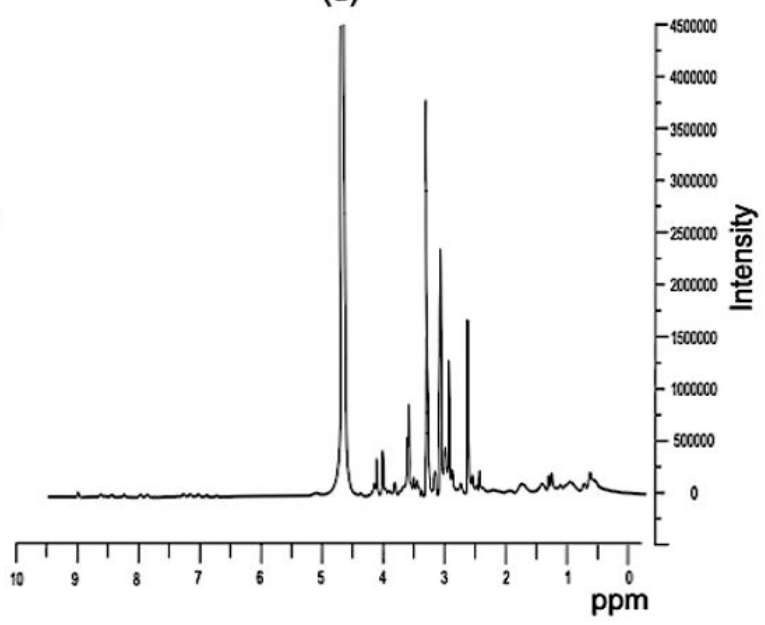

Figure 2. ${ }^{1} \mathrm{H}-\mathrm{NMR}$ spectra of pigment extracts from the skin of cephalopods: (a) methanolic extracts from octopus; (b) ethanolic extracts from octopus; (c) methanolic extracts from squid; (d) ethanolic extracts from squid. 


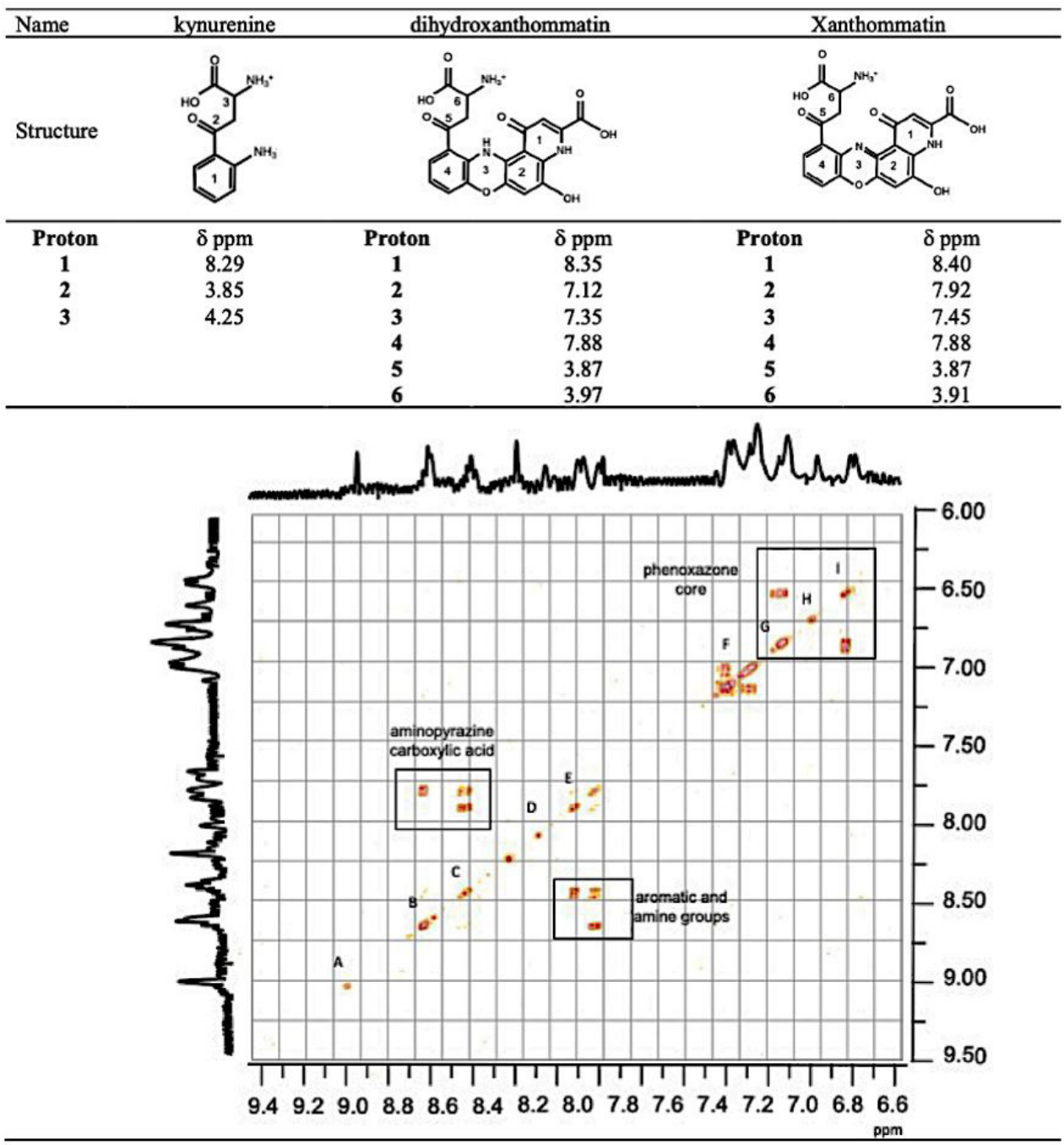

Figure 3. Structures of the identified ommochrome pigments in the skin of cephalopods. The chemical shift $\delta$ (ppm) and correlated homonuclear spectroscopy (COSY) spectrum ( $\delta$ 9.0-6.5 ppm spectrum portion) obtained using ${ }^{1} \mathrm{H}-\mathrm{NMR}$.

dihydroxy-12H-pyrido[3,2-a]phenoxazine-3-carboxylate (crosspeaks $\mathrm{E}, \mathrm{G}, \mathrm{H}$, and I), in addition to protons associated with 2-amino-4-(2-aminophenyl)-4-oxobutanoic acid dl-kynurenine 3-anthraniloylalanine (cross-peaks A, B, C). This type of compound was found previously in the skin of some cephalopods (Bolognese \& Scherillo, 1974; Bolognese \& Liberatore, 1988; Chan-Higuera et al., 2019c).

By calculating the integrals of signals detected in the area mentioned above, the ratio of the relationship between xanthommatin, dihydroxanthommatin, and kynurenine was established in each of the extracts studied. Although no differences were obtained in the proportions of the two main antioxidant ommochromes identified to date, xanthommatin and dihydroxanthommatin (Chan-Higuera et al., 2019c), a higher proportion of kynurenine, which may act as an effective electron donor (Romero \& Martínez, 2015), and a lower ratio in the aromatic amino acid groups $(\delta 5.0-3.0 \mathrm{ppm})$, were detected in the squid skin pigmented extracts compared with those from octopus (Figure 2). With regards to the solvents, a higher ratio in the section from $\delta 9.0$ to $6.5 \mathrm{ppm}$ was observed when
methanol-HCl (T1) was used, which suggests that this solvent has more affinity for aromatic protons and amino group protons. The latter observation cannot be used for absolute quantification of the compounds but generates relative estimations about the structural composition of the pigments.

\subsection{In vitro antioxidant activity of the skin pigments extracts}

Among the antioxidant analysis commonly used for evaluating the potential antioxidant activity in compounds extracted from foods or biological systems are the following: DPPH and ABTS radical assays, FRAP, and ORAC that evaluate the radical chainbreaking ability of antioxidant by measure the inhibition of reactive oxygen species-induced oxidation. Consequently, in this study, these tools were applied to assess the potential antioxidant activity of ommochrome pigments obtained from octopus and squid skin and using acidified methanol and acidified ethanol as the extraction solvent (Table 1).

The DPPH activity of the methanol and ethanol extracts of OVS and DGS was dose dependent. An examination of 
Table 1. Antioxidant activity of Octopus vulgaris and Dosidicus gigas skin pigments extracted with two solvents (methanol-HCl, T1 and ethanol$\mathrm{HCl}, \mathrm{T} 2)$.

\begin{tabular}{|c|c|c|c|c|}
\hline \multirow{2}{*}{ Determination } & \multicolumn{2}{|c|}{ O. vulgaris } & \multicolumn{2}{|c|}{ D. gigas } \\
\hline & T1 & $\mathrm{T} 2$ & $\mathrm{~T} 1$ & $\mathrm{~T} 2$ \\
\hline $\mathrm{IC}_{50} \mathrm{DPPH}(\mathrm{mg} / \mathrm{mL})$ & $0.48 \pm 0.04^{\mathrm{Bb}}$ & $1.24 \pm 0.03^{\mathrm{Ba}}$ & $1.14 \pm 0.02^{\mathrm{Ab}}$ & $1.74 \pm 0.04^{\mathrm{Aa}}$ \\
\hline $\mathrm{IC}_{50} \operatorname{ABTS}(\mathrm{mg} / \mathrm{mL})$ & $0.52 \pm 0.01^{\mathrm{Bb}}$ & $0.99 \pm 0.04^{\mathrm{Ba}}$ & $1.11 \pm 0.02^{\mathrm{Aa}}$ & $1.01 \pm 0.02^{\mathrm{Ab}}$ \\
\hline FRAP $(\mathrm{TE} \mu \mathrm{mol} / \mathrm{g})$ & $304 \pm 32^{\mathrm{Aa}}$ & $124 \pm 13^{\mathrm{Bb}}$ & $185 \pm 42^{\mathrm{Ba}}$ & $145 \pm 27^{\mathrm{Ab}}$ \\
\hline ORAC $(\mathrm{TE} \mu \mathrm{mol} / \mathrm{g})$ & $420 \pm 46^{\mathrm{Aa}}$ & $240 \pm 8^{\mathrm{Bb}}$ & $301 \pm 37^{\mathrm{Ba}}$ & $261 \pm 45^{\mathrm{Ab}}$ \\
\hline
\end{tabular}

Values represent the mean \pm standard deviation of four replicates. Capital letters indicate differences due to the effect of the source of extraction $(p \leq 0.05)$. Lowercase letters denote differences due to a treatment effect $(p \leq 0.05)$.

the Table 1 reveals that the $\mathrm{IC}_{50}$ antioxidant measured by this method, ranged from 0.48 to $1.74 \mathrm{mg} / \mathrm{mL}$, indicating that all extracts can scavenge the radical to a certain extent. Octopus vulgaris methanolic pigments extracts had the lower $\mathrm{IC}_{50}$ value $(0.48 \mathrm{mg} / \mathrm{mL})$, indicating that OVS-T1 possess greater DPPH radical scavenging capacity than other extracts $(p \leq 0.05)$.

In the ABTS assay the reduction of the ABTS $\bullet^{*}$ radical by antioxidants in the ommochromes pigments extracts generated an $\mathrm{IC}_{50}$ from 0.52 to $1.11 \mathrm{mg} / \mathrm{mL}$. The lowest $\mathrm{IC}_{50}$ value was observed for Octopus vulgaris methanolic extracts $(0.52 \mathrm{mg} / \mathrm{mL})$ and highest for Dosidicus gigas ethanolic pigments extracts $(1.11 \mathrm{mg} / \mathrm{mL})(p \leq 0.05)$.

It is to be noted that the values of DPPH and ABTS trend was dependent of the solvent employed. The $\mathrm{IC}_{50}$ for both cephalopods (O.vulgaris and D. gigas) was statically similar $(p>0.05)$ by DPPH and ABTS assay when methanol-HCl (T1) was used as solvent, but with ethanol- $\mathrm{HCl}$ (T2) the $\mathrm{IC}_{50}$ was lower $(p \leq 0.05)$ in ABTS. These differences can be related to the fact that DPPH has more affinity if the compounds are dissolved in methanol (Sharma \& Bhat, 2009). The antioxidant capacity of some natural compounds determined by the $\mathrm{IC}_{50}$ of $\mathrm{DPPH}$ and ABTS assays in shrimp by-product extracts ranges from 1.43 to $7.94 \mathrm{mg} / \mathrm{mL}$ (Kim et al., 2014), and in D. gigas ommochrome extracts from 2.6 to $10.2 \mathrm{mg} / \mathrm{mL}$ (Chan-Higuera et al., 2019c). The DPPH and ABTS assays indicated that the obtained pigments extract operates through hydrogen atom transfer (HAT) and an electron transference mechanism that reduce oxidant compounds (SET) reactions.

Similarly, the use of methanol- $\mathrm{HCl}$ or ethanol- $\mathrm{HCl}$ affected the extraction of compounds with FRAP and ORAC capacity. The highest FRAP and ORAC values were observed in methanolic pigments extracts (Table 1). It is noted that higher values imply higher antioxidant activity. Regarding the cephalopod species evaluated, the methanolic extracts from $O$. vulgaris showed higher antioxidant activity than D. gigas $(p \leq 0.05)$. However, D. gigas ethanolic pigments extracts showed highest values than O. vulgaris $(p \leq 0.05)$.

The SET capacity of Loligo formosana melanin (Vate \& Benjakul, 2013), olive mill waste waters (Jimenez-Alvarez et al., 2008) and methanolic extract from guava fruit (Thaipong et al., 2006) measured using the FRAP assay were $171 \mu \mathrm{mol} \mathrm{TE} / \mathrm{g}$, $319 \mu \mathrm{mol} \mathrm{TE} / \mathrm{g}$, and $21.3 \mu \mathrm{mol} \mathrm{TE} / \mathrm{g}$ respectively. Whereas the HAT capacity in methanolic extracts from jumbo squid skin (Chan-Higuera et al., 2019a), olive mill waste waters (JimenezAlvarez et al., 2008), and methanolic extract from guava fruit
(Thaipong et al., 2006) assessed by ORAC were $178 \mu \mathrm{mol} \mathrm{TE} / \mathrm{g}$, $1723 \mu \mathrm{mol} \mathrm{TE} / \mathrm{g}$, and $26.1 \mu \mathrm{mol} \mathrm{TE} / \mathrm{g}$, respectively.

Therefore, the antioxidant activity of the pigmented extracts was considered adequate, particularly that of methanolic extracts. These results are supported by the work of Cruz-Ramírez et al. (2015), who reported that methanol is one of the most effective organic solvents for extracting bioactive compounds from octopus (Paraoctopus limaculatus). Although more studies are necessary, the high antioxidant potential of extracts obtained using methanol- $\mathrm{HCl}$ could be explained by the high presence of aromatic protons and amino group protons in these extracts.

The extraction efficiency of bioactive compounds depends on, among other factors, the extraction solvent (Ngo et al., 2017). Whether an antioxidant compound is soluble in a given solvent depends on its chemical characteristics, including polarity. Methanol is efficient and widely used to obtain antioxidant extracts because it has a higher dielectric constant and polarity than ethanol (Mohsen-Nia et al., 2010), making it the most effective solvent in the extraction of antioxidant properties from seaweeds (El-Din \& El-Ahway, 2016). However, methanol has a higher toxicity than ethanol. Thus, the next phase of our research work was comparing the toxic effect of the extraction solvents in the bioactive methanolic and ethanolic pigments extracts.

The methodology used to prepare extracts from food and natural sources is the critical factor affecting the antioxidant activity of such extracts. It may induce the extension of the electronic delocalization of the extracted molecules (MohsenNia et al., 2010). Given the fact that the antioxidant capacity of the main pigments reported in squid skin (ommochromes) is associated with primary and secondary amino groups present in the aromatic rings (Chan-Higuera et al., 2019c), these conditions imply that the molecules obtained with T1 may be more reduced ommochromes, and have better antioxidant capacity, than those obtained with T2. Moreover, although more studies are needed, the differences detected in kynurenine and aromatic amino acid groups suggest that pigments with the highest proportion of aromatic groups and the smallest proportion of kynurenine could be related to higher antioxidant activity detected in OVS-T1 treatment.

\section{Conclusions}

The present study confirmed that the main compounds extracted from octopus and squid skin pigments are ommatins, specifically xanthommatin and dihydroxanthommatin, in addition to kynurenine. The extraction solvent exerted an essential 
impact on the extraction of antioxidant compounds from the samples. Acidified methanol was most efficient than acidified ethanol to extract oxidant compounds which can effectively scavenge various reactive oxygen species/free radicals under in vitro conditions. Pigments from octopus exhibited remarkable antioxidant activity. The most significant antioxidant activity was found in octopus skin pigments, likely due to the presence of amino-aromatic compounds. As a consequence, further research must address the identification of the active compounds, as well as to establish the capacity of the obtained extracts to delay lipid oxidation in food like pâtes, patties, deep-fried products, among other, becoming the new focus for the ongoing studies in our research group.

\section{Acknowledgements}

Authors recognize Consejo Nacional de Ciencia y Tecnología (CONACYT) Mexico for financing the project 2174 and for the graduate scholarship granted to Dania Marisol Esparza-Espinoza.

\section{References}

Aryee, N. A., \& Boye, J. I. (2015). Current and emerging trends in the formulation and manufacture of nutraceuticals and functional food products. In J. I. Boye (Ed.), Nutraceutical and functional food processing and technology (Chap. 1, pp. 1-60). New Jersey: John Wiley \& Sons. http://dx.doi.org/10.1002/9781118504956.ch1.

Asioli, D., Aschemann-Witzel, J., Caputo, V., Vecchio, R., Annunziata, A., Næs, T., \& Varela, P. (2017). Making sense of the "clean label" trends: a review consumer food choice behavior and discussion of industry implications. Food Research International, 99(1), 58-71. PMid:28784520.

Aubourg, S. P., Torres-Arreola, W., Trigo, M., \& Ezquerra-Brauer, J. M. (2016). Partial characterisation of jumbo squid skin pigment extract and its antioxidant potential in a marine oil system. European Journal of Lipid Science and Technology, 118(9), 1293-1304.

Aziz, M., \& Karboune, S. (2018). Natural antimicrobial/antioxidant agents in meat and poultry products as well as fruits and vegetables: a review. Critical Reviews in Food Science and Nutrition, 58(3), 486-511. http://dx.doi.org/10.1080/10408398.2016.1194256 PMid:27437876.

Benzie, I. F., \& Strain, J. J. (1999). Ferric reducing/antioxidant power assay: direct measure of total antioxidant activity of biological fluids and modified version for simultaneous measurement of total antioxidant power and ascorbic acid concentration. Methods in Enzymology, 299, 15-27. PMid:9916193.

Bolognese, A., \& Liberatore, R. (1988). Photochemistry of ommochrome pigments. Journal of Heterocyclic Chemistry, 25(4), 1243-1246. http:// dx.doi.org/10.1002/jhet.5570250438.

Bolognese, A., \& Scherillo, G. (1974). Occurrence and characterisation of a labile xanthommatin precursor in some invertebrates. Experientia, 30(3), 225-226. http://dx.doi.org/10.1007/BF01934793 PMid:4824584.

Bradford, M. M. (1976). A rapid and sensitive method for the quantitation of microgram quantities of protein utilising the principle of proteindye binding. Analytical Biochemistry, 72(1-2), 248-254. http://dx.doi. org/10.1016/0003-2697(76)90527-3 PMid:942051.

Brand-Williams, W., Cuvelier, M. E., \& Berset, C. (1995). Use of a free radical method to evaluate antioxidant activity. LebensmittelWissenschaft + Technologie, 28(1), 25-30.

Chan-Higuera, J. E., Carbonell-Barrachina, A. A., Cárdenas-López, J. L., Kačániová, M., Burgos-Hernández, A., \& Ezquerra-Brauer, J. M. (2019a). Jumbo squid (Dosidicus gigas) skin pigments: chemical analysis and evaluation of antimicrobial and antimutagenic potential. Journal of Microbiology, Biotechnology and Food Sciences, 9(2), 349-353.

Chan-Higuera, J. E., Ezquerra-Brauer, J. M., Lipan, L., Cano-Lamadrid, M., Rizzitano, R., \& Carbonell-Barrachina, A. A. (2019b). Evaluation of Dosidicus gigas skin extracts as an antioxidant and preservative in tuna pâté. Foods, 8(12), 693. PMid:31861248.

Chan-Higuera, J. E., Santacruz-Ortega, H. D. C., Carbonell-Barrachina, Á. A., Burgos-Hernández, A., Robles-Sánchez, R. M., Cruz-Ramírez, S. G., \& Ezquerra-Brauer, J. M. (2019c). Xanthommatin is behind the antioxidant activity of the skin of Dosidicus gigas. Molecules, 24(19), 3420. PMid:31547094.

Cruz-Ramírez, S. G., López-Sainz, C. M., Rosas-Burgos, E. C., CincoMoroyoqui, F. J., Velázquez, C., Hernández, J., \& Burgos-Hernández, A. (2015). Antimutagenic, antiproliferative, and antioxidant effects obtained from octopus (Paraoctopus limaculatus). Food Science and Technology, 35(4), 722-728.

Daniels, E. V., \& Reed, R. D. (2012). Xanthurenic acid is a pigment in Junonia coenia butterfly wings. Biochemical Systematics and Ecology, 44, 161-163.

Deravi, L. F., Magyar, A. P., Sheehy, S. P., Bell, G. R., Mäthger, L. M., Senft, S. L., Wardill, J., Lane, W. S., Kuzirian, A. M., Hanlon, R. T., Hu, E. L., \& Parker, K. K. (2014). The structure-function relationships of a natural nanoscale photonic device in cuttlefish chromatophores. Journal of the Royal Society, Interface, 11(93), 20130942. PMid:24478280.

El-Din, S. M. M., \& El-Ahway, A. M. D. (2016). Bioactivity and physicochemical constituents of marine red seweeds (Jania rubens, Corallina mediterranea and Ptercladia capillacea). Journal of Taibah University of Science, 10(4), 471-484. http://dx.doi.org/10.1016/j. jtusci.2015.06.004.

Englert, G., Bjørnland, T., \& Liaaen-Jensen, S. (1990). 1D and 2D NMR study of some allenic carotenoids of fucoxanthin series. Magnetic Resonance in Chemistry, 28(6), 519-528.

Ezquerra-Brauer, J. M., Miranda, J., Cepeda, A., Barros-Velázquez, J., \& Aubourg, S. (2016). Effect of jumbo squid (Dosidicus gigas) skin extract on the microbial activity in chilled mackerel (Scomber scombrus). Lebensmittel-Wissenschaft + Technologie, 72, 134-140.

Ezquerra-Brauer, J. M., Miranda, J., Chan-Higuera, J., Barros-Velázquez, J., \& Aubourg, S. (2017). New icing media for quality enhancement of chilled hake (Merluccius merluccius) using a jumbo squid (Dosidicus gigas) skin extract. Journal of the Science of Food and Agriculture, 97(10), 3412-3419. PMid:28009054.

Fatimah, Z., \& Rabeta, M. S. (2017). Antioxidant and antimicrobial activities of squid ink powder. Food Research, 2(1), 82-88.

Fay, D. S., \& Gerow, K. A. (2013). A biologist's guide to statistical thinking and analysis. In O. Hobert (Ed.), The online review of C. elegans research biology. California: WormBooks. http://dx.doi. org/10.1895/wormbook.1.159.1.

Figon, F., \& Casas, J. (2018). Ommochromes in invertebrates: biochemistry and cell biology. Biological Reviews of the Cambridge Philosophical Society, 94, 156-183. PMid:29989284.

Francikowski, J., Krzyżowski, M., Kochańska, B., Potrzebska, M., Baran, B., Chajec, Ł., Urbisz, A., Małota, K., Łozowski, B., Kloc, M., \& Kubiak, J. (2019). Characterisation of white and yellow eye colour mutant strains of house cricket, Acheta domesticus. PLoS One, 14(5), e0216281. PMid:31059541.

Jimenez-Alvarez, D., Giuffrida, F., Golay, P. A., Cotting, C., Lardeau, A., \& Keely, B. J. (2008). Antioxidant activity of oregano, parsley, and olive mill wastewaters in bulk oils and oil-in-wate emulsions enriched in fish oil. Journal of Agricultural and Food Chemistry, 56(16), 7151-7159. PMid:18636737. 
Kim, S.-B., Yoon, N., Shi, K., \& Lim, C.-W. (2014). Antioxidant and cholinesterase inhibitory activities of the by-products of three pandalid shrimps. Fisheries and Aquatic Sciences, 17, 421-425.

Kiyomoto, R. K., Poon, M. C., \& Bowen, S. T. (1969). Ommochrome pigments of the compound eyes of Artemia salina. Comparative Biochemistry and Physiology, 29, 975-984.

Kumar, B., Tirkey, N., \& Kumar, S. A. (2017). Anti-nutrient in fodders: a review. Chemical Science Review and Letters, 6(24), 2513-2519.

Liu, S., Bell, G., Kuzirian, A., \& Forsythe, E. (2012). Separation and identification of chromatophore pigments in the skin of the cephalopod Loligo pealei. Retrieved from https://pdfs.semanticscholar.org/564f /40f28cb341995f82ce68216f2fea95d67d06.pdf

Mohsen-Nia, M., Amiri, H., \& Jazi, B. (2010). Dielectric constants of water, methanol, ethanol, butanol and acetone: measurement and computational study. Journal of Chemistry Solutions, 39, 701-708.

Morales, J., Montero, P., \& Moral, A. (2000). Isolation and partial characterisation of two types of muscle collagen in some cephalopods. Journal of Agricultural and Food Chemistry, 48(6), 2142-2148. PMid:10888512.

Ngo, T. V., Scarlett, C. J., Bowyer, M. C., Ngo, P. D., \& Vuong, Q. V. (2017). Impact of different extraction solvents on bioactive compounds and antioxidant capacity from the root of Salacia chinensis L. Journal of Food Quality, 2017, 9305047.

Özyurt, G. B., Duysak, O., Akamca, E., \& Tureli, C. (2006). Seasonal changes of fatty acids of cuttlefish Sepia officinalis L. (Mollusca: Cephalopoda) in the north eastern Mediterranean sea. Food Chemistry, 95(3), 382-385.

Prior, R. L., Hoang, H., Gu, L., Wu, X., Bacchiocca, M., Howard, L., Hampsch-Woodill, M., Huang, D., Ou, B., \& Jacob, R. (2003). Assays for hydrophilic and lipophilic antioxidant capacity (oxygen radical absorbance capacity (ORACFL) of plasma and other biological and food samples. Journal of Agricultural and Food Chemistry, 51(11), 3273-3279. http://dx.doi.org/10.1021/jf0262256 PMid:12744654.

Re, R., Pellegrini, N., Proteggente, A., Pannala, A., Yang, M., \& RiceEvans, C. (1999). Antioxidant activity applying an improved ABTS radical cation decolorisation assay. Free Radical Biology \& Medicine, 26(9-10), 1231-1237. http://dx.doi.org/10.1016/S0891-5849(98)003153. PMid:10381194.
Riou, M., \& Christidès, J.-P. (2010). Cryptic color change in a crab spider (Misumena vatia): identification and quantification of precursors and ommochrome pigments by HPLC. Journal of Chemical Ecology, 36(4), 412-423. PMid:20224921.

Romero, Y., \& Martínez, A. (2015). Antiradical capacity of ommochromes. Journal of Molecular Modeling, 21(8), 220. http://dx.doi.org/10.1007/ s00894-015-2773-3 PMid:26238086.

Sawada, H., Nakagoshi, M., Mase, K., \& Yamamoto, T. (2000). Occurrence of ommochrome-containing pigment granules in the central nervous system of the silkworm, Bombyx mori. Comparative Biochemistry and Physiology. Part B, Biochemistry \& Molecular Biology, 125(3), 421-428. PMid:10818276.

Shahidi, F., \& Zhong, Y. (2015). Measurement of antioxidant activity. Journal of Functional Foods, 18, 757-781.

Shahidi, F. (2006). Maximising the value of marine by-products (1st ed.). Cambridge: Woodhead Publishing.

Sharma, O. P., \& Bhat, T. K. (2009). DPPH antioxidant assay revisited. Food Chemistry, 113(4), 1202-1205. http://dx.doi.org/10.1016/j. foodchem.2008.08.008.

Thaipong, K., Boonprakob, U., Crosby, K., Cisneros-Zevallos, L., \& Hawkins Byrne, D. (2006). Comparision of ABTS, DPPH, FRAP, and ORAC assays for estimating antioxidant activity from guava fruit extracts. Journal of Food Composition and Analysis, 19(6-7), 669-675. http://dx.doi.org/10.1016/j.jfca.2006.01.003.

Van den Branden, C., \& Decleir, W. (1976). A study of the chromatophore pigments on the skin of the cephalopod Sepia officinalis L. Biologisch Jaarboek Dodonaea, 44(7), 345-352.

Vate, N. K., \& Benjakul, S. (2013). Antioxidative activity of melanin-free ink from splendid squid (Loligo formosana). International Aquatic Research, 5, 9.

Vodnar, D. C., Călinoiu, L. F., Dulf, F. V., Ştefănescu, B. E., Crişan, G., \& Socaciu, C. (2017). Identification of the bioactive compounds and antioxidant, antimutagenic and antimicrobial activities of thermally processed agro-industrial waste. Food Chemistry, 231(15), 131-140. PMid:28449989.

Zumholz, K., Hansteen, T. H., Klügel, A., \& Piatkowski, U. (2006). Food effects on statolith composition of common cuttlefish (Sepia officinalis). Marine Biology, 150(2), 237-244. http://dx.doi.org/10.1007/ s00227-006-0342-0. 